\title{
ACTION RESEARCH: Time to Take a Turn?
}

\author{
Briony J. Oates \\ University of Teesside
}

\begin{abstract}
Following the linguistic turn of social sciences in the $20^{\text {th }}$ century, some researchers are now taking a turn to action. They use action research but give it a broader meaning than that currently understood by many researchers in IS. This paper discusses the newer meaning of action research and indicates how it contrasts with some uses of action research reported in the IS literature. Five quality issues for the new action research are discussed: relational praxis, reflexive-practical outcome, plurality of knowing, significant work, and new and enduring consequences or infrastructure. The paper then gives a reflexive account of an IS research study that attempted to address these five issues. Finally, the paper discusses some of the broader implications for IS research of a turn to action.
\end{abstract}

Keywords: Action research, participation, metaphors, information systems development

\section{INTRODUCTION}

The 1984 IFIP WG 8.2 conference has been described as the occasion when some “"Young Turks'...set out to break the mold of orthodox IS research methodology" (IFIP WG 8.2 Call for Participation for the current conference). This was not just a move to promote qualitative data in IS research, but also a manifestation in IS of a phenomenon which took place last century across the social sciences, namely a change of paradigm in what has been called the linguistic turn. This turn brought the realization that there is a difference between the world itself and our interpreted experience of the world. It looked at the previously little-explored role of language in our construction of our world. In what has since become known as interpretivism, it was recognized that whatever reality is, it can only be accessed through social constructions such as language and shared meanings and understanding. For example, the scientific method based on positivism is itselfa social construction. Interpretive studies, therefore, examine people 
in their social settings and try to understand phenomena through the meanings that people assign to them. The aim is "an organized discovery of how human agents make sense of their perceived worlds, and how those perceptions change over time and differ from one person or group to another" (Checkland and Holwell 1998, p. 22).

Since the 1984 IFIP 8.2 conference, interpretivism has won increasing acceptance in IS. In their 1991 survey, Orlikowski and Baroudi (1991 p. 5) categorized just 3 percent of the IS research papers they studied as interpretive. However, in 1995, Walsham found evidence of increasing use and acceptance of interpretivism in IS. Avison (1997) suggested that, in Europe at least, the emphasis is increasingly on interpretive methods, and the figure for positivist research in IS would be less than 50 percent by the turn of the century. Mingers' (2003) recent survey of journals found only 18 percent of papers were interpretive. However, this percentage would have been higher if Mingers had included action research in the interpretive paradigm, as previous surveys had, rather than in what he calls an "intervention oriented" paradigm, and his survey was restricted to only six IS journals. Even if much IS research, particularly in the U.S., continues to be based on positivism, interpretivism has become the chosen paradigm for a significant number of IS researchers.

Meanwhile, however, some social sciences researchers have taken another turn-the turn to action (Reason and Bradbury 2001b). This accepts the idea of knowledge as a social construction, but then "asks us to consider how we can act in intelligent and informed ways in a socially constructed world" (Reason and Bradbury 2001b, p. 2). Its methodology is based on action research.

Action research has also received attention in IS. It was discussed at the 1984 conference in the context of the development of the Multiview methodology (WoodHarper 1985) and had already been used by Checkland (1981) in his development of soft systems methodology (SSM) and Mumford $(1978,1983)$ in her development of ETHICS. It has been used particularly, although not exclusively, for IS development methodologies (for example, Baskerville and Stage 1996; Baskerville and Wood-Harper 1996; Vidgen 2002). Other examples of its use include Scandinavian research aimed at empowering trade unions and users (Bjerknes et al. 1987), and the work of Mathiassen and his colleagues at Aalborg in Denmark (Mathiassen 1998). Comprehensive reviews of the use of action research in IS can be found in Baskerville and Wood-Harper (1998) and Lau (1997). Recent or planned special issues on action research in Information Technology and People (2001) and MIS Quarterly (forthcoming) are evidence of continuing, and perhaps increasing, interest in action research.

However, for social scientists who have taken the turn to action, action research has a broader meaning than that currently understood by many researchers in IS, in terms of scope, conceptual underpinnings, and forms of practice. This paper discusses how those who have taken the turn to action perceive action research - called here the new action research. It is structured around the five quality issues defined by Bradbury and Reason (2001), who currently offer the most detailed exposition of the emerging new action research (see also Reason and Bradbury 2001a, 2001b). This paper indicates how the new action research contrasts with some uses of action research reported in the IS literature. It suggests how IS action research could be enriched by the turn to action, and how such a turn would lead to a changed understanding of the nature of knowledge and a questioning of what is worthwhile research. The paper then illustrates this discussion 
via a reflexive account of an IS research study that attempted to follow the new action research principles. Finally, the paper discusses some of the broader implications for IS researchers of a turn to action.

\section{THE NEW ACTION RESEARCH}

The new action research is defined as

a participatory, democratic process concerned with developing practical knowing in the pursuit of worthwhile human purposes, grounded in a participatory worldview which we believe is emerging at this historical moment. It seeks to bring together action and reflection, theory and practice, in participation with others, in the pursuit of practical solutions to issues of pressing concern to people, and more generally the flourishing of individual persons and their communities (Reason and Bradbury 2001b, p. 1).

We can compare this with Rapoport's definition of action research, which is often cited in the IS literature.

Action research aims to contribute both to the practical concerns of people in an immediate problematic situation and to the goals of social science by joint collaboration within a mutually acceptable ethical framework (Rapoport 1970, p. 499).

It can also be compared with Kock's definition.

A general term to refer to research methodologies and projects where the researcher(s) tries to directly improve the participating organization(s) and, at the same time, to generate scientific knowledge (Kock 1997).

The new definition places less emphasis than the other two on contribution to scientific knowledge and greater emphasis on worthwhile purposes, participation, and individual human (rather than organizational) flourishing. These aspects are all discussed in this section.

Varieties of the new action research include action science (Torbert 1991), participatory (action) research (Fals-Borda 2001) and cooperative inquiry (Heron 1996). There is thus no single version, to seek one probably suggests a modernist or positivist stance and a quest for a single, objective truth. Instead, different researchers, while trying to meet all of the parts of the first definition, tend to emphasize different parts of it (for many examples, see Reason and Bradbury 2001a).

Bradbury and Reason (2001) suggest researchers should address five quality issues in the new action research: relational praxis, reflexive-practical outcome, plurality of knowing, significant work, and new and enduring consequences/infrastructure. Each of these is explained and discussed below. 


\subsection{Relational Praxis}

The defining characteristic of the emergent worldview of the new action research is participatory (Reason and Bradbury 2001b, p. 6). Our world is not made up of separate things, but of relationships, which we cocreate, participate in, and maintain. We cannot stand outside our world, we are necessarily already acting in it as we live and breathe. This worldview combines both positivism and interpretivism. Following positivism, it argues for a real reality, which is a state of being in the world, in which we all partake; following interpretivism, it acknowledges that as soon as we try to express this, we enter a maze of human language and socially constructed meanings (Reason and Bradbury 2001b, p. 7). The aim of the new action research is to support and enhance skills for being-in-the-world (Reason and Bradbury 2001b, p. 8). Given that we are all acting and being in the world, it also seeks to remove the researcher/subject distinction, aiming instead for a joint inquiry where people who share a problem come together to resolve it.

Heron (1996) argues that there are two complementary kinds of participation in research: political participation (concerning the relation between people in the inquiry and the decisions that affect them) and epistemic participation (concerning the relation between the knower and the known).

The arguments for political participation are (Heron 1996, p. 21)

- People have a right to participate in decisions about both the method and conclusions in research that seeks to formulate knowledge about them.

- It gives them the opportunity to express their own preferences and values in the research design.

- It empowers them to flourish fully as humans in the study, and be represented as such in its conclusions, rather than being passive subjects of the researchers.

- It avoids their being disempowered, oppressed and misrepresented by the researchers' values that are implicit in any unilateral research design.

The arguments for epistemic participation are (Heron 1996, pp. 20-21)

- Propositions about human experience are of questionable validity if they are not grounded in the researchers' experience.

- The most rigorous way to do this is for researchers to ground the statements directly in their own experience as co-subjects.

- Researchers cannot get outside, or try to get outside, the human condition in order to study it. They can only study it through their own embodiment, in joint participation and dialogue with others who are similarly engaged.

- This enables researchers to come to know not only the external forms of worlds and people but also the inner feelings and modes of awareness of these forms.

Heron criticizes quantitative, positivist research on people (pp. 25-26). Such research ignores the human right of people to participate in decisions about gaining knowledge of them (i.e., a lack of political participation). It also produces knowledge that is not 
experientially grounded: the researchers are not involved in the experience examined by the research, and the subjects are not involved in the selection of the constructs that are used to make sense of their experience (i.e., a lack of epistemic participation). Qualitative, interpretive research aboutpeople is also criticized where the research is designed and interpreted unilaterally by the researcher. However, interpretive researchers do include some participation (in the political sense) if they seek to validate their account with their respondents. Interpretive researchers can also be partially participant (in the epistemic sense) if they do fieldwork involving their own participation in the research setting, rather than being a detached observer. Often, however, decisions about what data to gather and the interpretive models used are not decidedjointly with the subjects. As Brechin writes (1993, p. 73),

Research tends to be owned and controlled by researchers, or by those who, in turn, own and control the researchers. Those who remain powerless to influence the processes of information gathering, the identification of truth, and the dissemination of findings are usually the subjects of the research, those very people whose interests the research may purport to serve.

Hence qualitative research about people is seen as a halfway house between exclusive, controlling research on people and fully participatory research with people (Heron 1996, pp. 26-30). The new action research calls for research with, for, and by people (Reason and Bradbury 2001b). This implies that everyone is capable of being a researcher; it is not the preserve of those in laboratories and universities. This can, in turn, lead to ordinary people realizing that

experts are not the objective, unbiased, disinterested purveyors of truth. Scientists often use "science" to impress or hide political decisions as "scientific." "Science" is not accountable and responsible to the needs of ordinary people but serves the power-holders (Lewis 2001, p. 361).

Recent public debate about the safety of the MMR vaccine or genetically modified crops are evidence of people's increased reluctance to accept scientists' statements unquestioningly.

Participation is often mentioned in the IS literature on action research. For example,

A major strand of action research is that the practitioners should participate in the analysis, design and implementation processes and contribute at least as much as researchers in any decision making (Avison and Wood-Harper 1990, p. 180).

It is not clear from the IS literature that those practitioners have always been active partners for all aspects of an action research project. It is often left unstated, for example, whether they took part in all decisions and reflections about the research methodology and any relevant theories. For example, in the Lancaster school's research into SSM (e.g., Checkland 1981; Checkland and Scholes 1990), it is not clear whether 
all organizational participants and the postgraduate students involved could choose not to use SSM. (For a discussion of aspects of control in action research projects see Avison et al. 2001.)

The particular type of action research known as participatory action research is sometimes cited in the IS literature; for example, the work of Fals-Borda (2001), who has concentrated on liberationist inquiry in underprivileged communities, helping people to understand knowledge as an instrument of power and control, and seeking to raise their consciousness and empower them. But his approach seems to be treated as an interesting alternative to business-based action research, rather than a demonstration of a fundamental part of the worldview of action research. Instead, in IS the interests of an action researcher's co-participants seem often to be conflated with the interests of the organization as, for example, in Kock's definition of action research at the beginning of this section or Baskerville's (1999) definition: "The researcher is actively involved, with expected benefit for both researcher and organization."

Organizations do not have needs. What are called organizational needs are formulated by powerful groups within the organization (Howcroft and Wilson 2003), possibly to the detriment of others.

There has also been a tradition of participatory design in IS development, developed via action research, especially in Scandinavia (e.g., Bjerknes et al. 1987; Howard 1985). However, participatory approaches too are criticized for not addressing conflict problems from the unequal distribution of power and the irreconcilability of management and worker needs, and for being managerialist in not challenging the power or legitimacy of managers' right to manage (Howcroft and Wilson 2003).

For new action research in business organizations, a goal of improved performance would not be superior to that of human flourishing. This could cause problems for IS action researchers who are based in business schools where managers are seen as the primary clients and research is focused on economic goals.

Explicit attention to the relational praxis issue could enrich IS action research by focusing attention on genuine participation by all affected and studied.

\subsection{Reflexive-Practical Outcome}

The new action research aims at practical outcomes, as well as conceptual knowledge, asking, for example, "Do people whose reputations and livelihoods are affected act differently as a result of the inquiry?" This applies as much to academic researchers as to other participants, suggesting the need for researchers to provide confessional accounts of their action research.

Drawing on Habermas, Kemmis (2001) (also Carr and Kemmis 1986) distinguishes between three kinds of action research and outcomes: technical, practical, and emancipatory. Much action research (in IS and across the social sciences) is technical, concentrating on functional improvements. For example, Kock et al. (1997) discuss an action research study that investigated the thesis that "groupware systems would positively affect productivity and quality of project-related activities." Technical action research would not normally question the goals themselves, nor how the situation in which the action research is being performed has been discursively, socially, and historically constructed (Kemmis 2001, p. 92). 
Practical action research is influenced by Schön's (1983) ideas of the reflective practitioner. It has technical aspirations for change, but also aims to inform the practical decision making of the people involved in the research. They aim to improve their functional practice, but also to reflect on and understand how their goals, and the criteria they use for evaluating their practice, are shaped by their own ways of seeing themselves and their context. The research process becomes a form of self-education and the focus is as much on changing themselves as the subjects (or authors) of a practice as changing the outcomes of their practice (Kemmis 2001, p. 92). Examples can be found in researchers' subjective and confessional accounts of their reflections and personal learning during action research projects (e.g., Mumford 2001).

Emancipatory action research aims to improve technical performance, and the selfunderstanding of those involved, but also to help them critically evaluate their social or organizational context. They should understand how their functional goals may be limited or inappropriate within a wider view of the situation in which they live or work, and how their self-understandings may be shaped by shared misunderstandings about the nature and consequences of what they do. It aims to "connect the personal and the political in collaborative research and action aimed at transforming situations to overcome felt dissatisfactions, alienation, ideological distortion, and the injustices of oppression and domination" (Kemmis 2001, p. 92). Examples of this type of action research can be found in the women's, civil rights, and land rights movements. In IS, emancipation has been a goal for some researchers, who work within what is summarized as the critical paradigm (Orlikowski and Baroudi 1991). Although Orlikowski and Baroudi found no examples of critical studies and later Walsham (1995) found only a few, recently there has been an increasing number of papers, workshops, and conferences in the critical paradigm (e.g., Adam et al. 2001). However, much of the work in this critical paradigm tends to be analytical, identifying the structures, conventions, and contradictions that prevent human flourishing, without practically empowering those under study to recognize and overcome these barriers (e.g., Howcroft and Wilson 2003). Specifically using action research there have been a few emancipatory projects. For example, Waring $(2000,2002)$ initially investigated the continuing failure of NHS hospitals to implement integrated information systems but over time focused on emancipation and the role of the systems analyst within IS implementations, adopting a feminist gender lens.

Kemmis (2001; also Carr and Kemmis 1986) places these three types of action research in a hierarchy, with emancipatory action research as the most desirable. However, as Webb (1996) points out, all the words used to promote the ideals of such action research (such as emancipation, autonomy, democracy, consensus, rationality, solidarity, social justice, and community) are themselves problematic and contestable. Power is always present in any group, and cannot be dispersed by rationality; rationality and rational consensus often serve the interests of the powerful; and each of us plays multiple roles of both privilege and oppression. Emancipation is, therefore, neither simple, nor necessarily always desirable.

Explicit attention to the reflexive-practical outcome issue could enrich IS action research by focusing attention on the effect of the research on the researchers, whether technical, practical and emancipatory outcomes of the work are desirable and feasible, and whose interests the research serves. 


\subsection{Plurality of Knowing}

Ways of knowing in new action research are aimed at supporting skills for being-inthe-world (Reason and Bradbury 2001b, p. 8). It is argued that the knowledge emerging from the new action research should have conceptual-theoretical integrity, embrace ways of knowing beyond the intellect, and choose appropriate research methods for finding these multiple ways of knowing.

Action research in IS has also placed strong emphasis on theoretical underpinnings and on outcomes that further contribute to theory. For example,

The theoretical framework must be present as a premise, otherwise the intervention action is no longer valid as research. The diagnosis document should include explicit theoretical foundations. As the research progresses, the emergence of theory should be recorded carefully in the research notebooks (Baskerville 1999).

For example, soft systems methodology is based on general systems theory, and the action research on SSM led to a reconceptualizing of system in an epistemological sense rather than an ontological sense (Checkland and Holwell 1998).

However, the conceptual or intellectualized forms of knowledge as commonly used and produced in academia is not seen as the only form of knowledge outcome in the new action research. The new action research recognizes at least four different types of knowledge (Heron 1996, pp. 52-58;Heron and Reason 2001;Reason 1994a, pp. 42-46).

- Experiential knowledge — gained by direct encounter; almost impossible to put into words, being tacit and based on empathy, intuition and feeling

- Presentational knowledge - emerges from experiential knowledge; gives the first expression of knowing something through stories, drawings, sculpture, music, dance, etc.

- Propositional knowledge - about something in the form oflogically organized ideas and theories, as in most academic research

- Practical knowledge - evident in knowing how to exercise a skill

These types of knowing require a wider range of methods than commonly found in action research in IS, such as song, dance, and exploring emotions. Since the world view is based on being-in-the-world, it follows that the full range of human sensibilities are appropriate to ways of finding out about fully being and acting in the world. This is likely to cause problems for many researchers who have been trained to remove the subjective and irrational from their research. Compare, for example, Baskerville's rejection of emotion (because it interferes with learning from the research) with Treleaven's welcoming of emotion (because it leads to new knowledge and action).

The domain [of action research] excludes settings where explicit theoretical frameworks become excluded as the basis for action. A practical implication of this exclusion means that highly emotional social settings where rational 
action planning cannot be shared among the participants, will interfere with the learning from the research (Baskerville 1999).

[Our collaborative inquiry methodology] challenged gendered emphasis placed on rationality in more traditional forms of action research. As participants with emotions and bodies which are themselves often ignored sources of our knowing...we made space in our workplace enquiry to attend to both.... Emotions that accompanied our stories - anger, despair and grief as well as joy with its laughter and well-being-were catalysts to new understanding and acting (Treleaven 2001, p. 262).

Explicit attention to the plurality of knowing issue could enrich IS action research by including the emotional, intuitive, and artistic skills of being in the world.

\subsection{Significant Work}

It is argued that new action researchers should focus on how they choose where to put their efforts (Bradbury and Reason 2001, p. 452). Worthwhile research will be that which is well-grounded in the everyday concerns of people, and may be seen as increasing in significance as it moves beyond the technical to developing people's capacity to ask fundamental questions about their world. Researchers and readers should ask how the action research helps to call forth a world worthy of human aspiration, so that people might say "that work is inspiring, that work helps me live a better life" (Bradbury and Reason 2001, p. 449).

Conventional IS action researchers who are accustomed to providing knowledge to support organizational objectives (or objectives of the organization's powerful) may find their research challenged by new action researchers who question whether it is worthwhile research. Explicit attention to the significant work issue could enrich IS action research by focusing attention on the kinds of research questions researchers choose to address.

\subsection{New and Enduring Consequences or Infrastructure}

New action research should also have consequences that endure. These can include new practical and academic knowledge but there are other possibilities too. For example, Bradbury and Reason (2001) ask whether those involved can say, "This work continues to develop and help us." They also ask, "Has the work been seeded so that it can be continued participatively if the initiating researcher moves away?" and, "Does it leave behind new patterns of behavior within a group, or new structures such as centers for action research?" and can others say, "We can use your work to develop our own."

In IS, successful action research is expected to be judged by two criteria: practical achievements in the problem situation and/or learning about the process of problem solving (Checkland and Scholes 1990). Explicit attention to the new and enduring consequences issue could enrich IS action research by recognizing more types of 
consequences, such as community ties or other forms of social capital, sustainability, and critical awareness.

\section{EXAMPLE: A COOPERATIVE INQUIRY INTO METAPHORS}

To illustrate the discussion above, this section provides a reflexive account of a study that was based upon the new action research approach using the five quality issues explained above. (For further detail of the study, see Oates 2000, 2002.)

\subsection{Background and Motivation}

The study involved four participants (myself as a full-time lecturer and part-time Ph.D. student and three systems developers, who were also students). Through cycles of action and reflection, we explored the extent to which conventionally educated information systems developers could adopt a richer model of organizations by using metaphors for organizations, derived in the main from Morgan $(1986,1993)$ as cognitive structuring devices, and we examined whether the metaphors had relevance for IS development practice.

For this action research, we were developing a theory: the use of organizational metaphors during ISD. We were also developing professional practice- the work of systems developers-and examining whether it could include metaphors to conceptualize their client organizations. Since the project also involved the development of information systems for three organizations, we were concerned with institutional change and development. We were also concerned with our individual learning and development.

My three coresearchers (Alan, Marcus, and Peter) had an average of three years of experience with ISD. They were currently computing degree students in their final year of studies but would return to IS developer roles on completion of their studies. An earlier action research study conducted by a master's student and myself had raised in my mind concerns about the uneven power relationship between lecturers and their research students (Oates 1999, 2000). Did the students' lower status militate against authentic collaboration, and how could academics guard against students reporting outcomes favorable to an academic's favored theory or methodology in the hope of gaining approval and better assessment grades?

I had therefore decided that for any future study involving a student as coresearcher I would work with a group of students. A group would at least help to redress the power imbalance; they would have some peer support and outnumber me as their lecturer. I decided to use cooperative inquiry (CI), a type of new action research, as my research strategy, because it is aimed at group research, where knowledge arises through action andjoint reflection, with an emphasis on participation by all affected. The most comprehensive guide to CI is Heron (1996). (Additional sources include Heron and Reason 2001; Reason 1988, 1994b, 1994c; Reason and Bradbury 1999, 2001b; Reason and Rowan 1981.)

As recommended by Heron (1996, p. 102), the group agreed that each member of the CI group was free to write an account of the inquiry without submitting a draft to the 
others, but should make this limitation clear. This account has not been written collaboratively with the group. This is clearly a limitation on any claim that the research findings are based on authentic collaboration.

\subsection{Relational Praxis}

My coresearchers would return to ISD roles after their studies. Hence they were potential beneficiaries of the research ideas, who should be enabled to participate in its development, evaluation, and dissemination. They had been invited (not coerced) to take part. However, I was concerned about how far the research would be truly participative. My concerns about authentic collaboration included

- whether my academic language, and position of authority over the student coresearchers, might get in the way

- whether doing research initiated to meet my needs would be useful to them

- how to use my expertise in relation to metaphors for organizations and research, and yet do the research collaboratively

- how much I would control what the group did, and how much I could let go, i.e., how collaborative $I$ could be

To deal with these concerns, I

- discussed the problem at the first group meeting and explored strategies they could use if I lapsed into lecturer mode

- arranged meetings not in my office but a spare classroom, which was more neutral ground

- ensured all had access to the same data (I circulated my notes on each meeting and deliberately chose not to tape record our meetings, which would have reinforced the idea that I was in charge: setting up the recorder and lending tapes to the coresearchers)

- asked the others what they thought before giving my views, even when questions were directed to me

Eventually I realized I had to accept that a power balance was inevitable, but each of us brought different knowledge and experience to the group. I had more knowledge of research and the use of metaphors, but they had greater expertise of the technical aspects of ISD. I needed their involvement to explore the use of metaphors in practice, but they needed my involvement to help them complete a satisfactory project for their degrees. CI does not imply equality, rather, each brings experiences and skills to the group and is willing to share and develop them collaboratively. At the beginning, I had to take the initiative, but through my actions and sharing my thinking, I could help the others take more control.

This issue of achieving authentic collaboration is discussed in many of the CI accounts (e.g., Marshall and McLean 1988; Traylen 1994; Treleaven 1994), and indeed is a significant issue in all non-positivist research (see Lincoln 1998; Lincoln and Denzin 
1994). It is an unavoidable challenge where the research was initiated externally by researchers who, obviously, have their own needs or objectives which might not fully coincide with those of the other participants.

Indicators of our successful collaboration and the move from dependence on me as leader include

- increasingly those who arrived first started discussing project issues and did not break off on my arrival

- $\quad$ each of the others led discussions, suggested ideas to the others, and proposed metaphor-based views

It was a concern that I did not participate fully in the experience and action of ISD in the client organizations (epistemic participation). A resolution of this was suggested by Traylen (1994). She helped health visitors explore their hidden agendas in their meetings with clients, but was not a practicing health visitor herself. She realized that she too had hidden agendas in her meetings with the health visitor coresearchers. These could be explored as part of the research, increasing her epistemic participation. Similarly, I realized that I could think of our group as a small organization, and investigate how Morgan's metaphors helped me conceptualize it (see Oates 2000).

I felt there had been authentic collaboration. I also invited the coresearchers to complete a questionnaire anonymously, after the end of our inquiry. Their responses show each was happy with the group process and its findings on metaphors, and no one thought anyone had dominated the discussions.

I feel the CI study did achieve authentic participation among the coresearchers and myself. However, what of others affected by the research? Each of the student coresearchers interacted with people in their client organizations. They were consulted about the information systems being developed, but only in order to develop improved information systems. We did not consider whether a new information system might somehow enhance or prevent their human flourishing. We did agree we should share with people in the client organizations the metaphor ideas. However, each of the coresearchers found it difficult to explain the use of metaphors to others, encountering incomprehension and even derision, so this was not successful. Members of the organizations were not involved in our use of metaphors to understand them. Reflections on the relational praxis issue therefore highlighted this limitation of the study.

\subsection{Reflexive-Practical Outcome}

Tangible outcomes from the research were working information systems for the three client organizations and student success - each student coresearcher passed the project part of his degree and went on to gain a B.Sc. honors degree, and I ultimately gained my Ph.D. (Oates 2000).

As explained earlier, Kemmis (2001) defines three types of action research outcomes: technical, practical, and emancipatory. This study had a technical focus: developing a systems development methodology that used organizational metaphors to 
enable a richer view of organizations than that found in conventional systems development. A technical outcome was a prototype methodology (MMM, or multiple metaphor methodology) that we created and refined (Oates 2000).

The study also had practical outcomes in Kemmis' sense of self-education. We each learned abut how we liked to work and research. The student coresearchers all reported that they had enjoyed the group-based research. They felt it was a better way of working than the one-to-one (supervisor-to-student) mode normally used to support student projects because

- $\quad$ group meetings were less intense, stressful, and pressured

- $\quad$ each had the opportunity to sit back and relax, or think things through, while others discussed their projects

- $\quad$ each learned from the others, and there were richer discussions

I too found I enjoyed the cooperative inquiry, and I learned that I could reduce my control when working with a student group, gradually abandoning careful plans for each meeting and trusting that learning would emerge from a more unstructured approach where others could take the lead.

Emancipatory outcomes are concerned with those involved critically evaluating their social or organizational context. As discussed above, we did not address this aspect with respect to the employees of our client organizations. We did, however, become critical about our own situations. The student coresearchers criticized the limited education they had received about organizations. Their degree courses (computer science for two, information technology for the third) had concentrated on technical skills and knowledge, yet their future careers would almost certainly entail operating within the complex, dynamic, and fuzzy organizations made up of, and constructed by, people, for which they were ill-equipped. Through reading about, and performing, cooperative inquiry, I became more convinced that we can all be researchers into our own lives and practices, and research should not be restricted to an elite group.

Attention to the reflexive-practical outcomes issue, therefore, highlighted not only tangible, practical outcomes but also self-knowledge and critical awareness outcomes.

\subsection{Plurality of Knowing}

The work had strong conceptual-theoretical underpinnings. It drew on Morgan's well-established work on organizational analysis via metaphors as well as cognitive psychology theories about how we think via metaphors (e.g., Holyoak and Thagard 1996).

Propositional knowledge was developed as we used metaphors to structure and articulate interpretations of the three client organizations. On the basis of each interpretation, assertions were made about the organizations and/or actions were taken. Qualitative, interpretive accounts were produced, which explored our joint sense-making via metaphors and established the relevance of organizational metaphors to ISD practice in the context of our three client organizations. These can be found in Oates (2000) and the coresearchers' individual project reports (Findlay 1998; Lyons 1998; Thomas 1998). 
The other three types of knowledge identified by Heron were also gained. Experiential knowledge was gained in both using metaphors and collaborating in research. We were each changed by having participated in the cooperative inquiry and the systems development projects. Presentational knowledge was produced when we told stories of events we had experienced or observed in organizations. We also used diagrams and other pictures to explore our understanding of the organizations. However, none of us used more artistic forms of expression such as poetry or music. Practical knowledge was gained by each member in learning how to map the metaphors to organizations and link the mapping to ISD issues.

We did allow space for emotions within our inquiry. We frequently laughed as we told stories of our experiences, and we acknowledged when we were feeling tired and had (temporarily) lost interest in the research. We also discussed our anxieties. At the first meeting, we discussed our worries about doing the research and writing reports and a thesis. Later worries we discussed included course demands and uncertainties about future career plans. Hence the group members provided support for each other beyond producing academic, propositional knowledge.

Attention to the plurality of knowing issue provided opportunities to use a wider range of inquiry skills and recognize a variety of knowledge outcomes.

\subsection{Significant Work}

The study enabled us to practice a method of taking greater account of organizations and the people within them, who were not seen as just cogs in a machine. Through using the metaphors, we were able to articulate richer conceptualizations of the organizations and employees, including their politics and cultures. We were able to identify how these richer conceptualizations did not just lead to greater understanding, but also influenced both our systems development process and product, leading to systems which took greater account of human needs and should mesh better with their social and organizational contexts. As discussed in the outcomes section above, we all also learned something about ourselves and our work and educational situation. I believe the research was worthwhile and significant.

Reflecting on the significant work issue made me consider whether I was justified in involving others in answering my research questions and whether the research aim was really worthy of attention.

\subsection{New and Enduring Consequences}

The rationale for the work, its conceptual underpinning and its research outcomes are discussed in Oates (2000) and are available for others to try out and evaluate in their own studies. Our process of cooperative inquiry is discussed and evaluated in Oates $(2000,2002)$ so that others can reconstruct the process and amend it to suit their own group. The student coresearchers have also written accounts of their experience and findings (Findlay 1998; Lyons 1998; Thomas 1998), which other students have consulted. The information systems we developed continue to be used.

The group itself did not endure beyond the end of the coresearchers' studies; each has taken up a position elsewhere in the country. However, each has taken with them 
an understanding of the use oforganizational metaphors and their potential relevance to their systems development practice. One has since reported transferring the approach to a new situation. Follow-up research could find out whether and how they have used the approach in their new jobs.

Through reflecting on cooperative inquiry and the new action research, I also recognized my own preferences about types of research. I now prefer projects within the public, voluntary, and community sectors, where I have found greater openness than in the business sector to ideas of human flourishing.

Reflecting on the enduring consequences issue highlighted for me the study's consequences beyond answering the original research questions.

This section has illustrated the use of the five quality issues and demonstrated some of the possibilities offered by the new action research.

\section{SUMMARY AND IMPLICATIONS}

This paper has discussed the new action research, and illustrated the discussion by means of a confessional account of an action research study. The paper was structured around five quality issues: relational praxis, reflexive-practical outcome, plurality of knowing, significant work, and new and enduring consequences or infrastructure.

Implications for IS researchers of specifically addressing these five issues are

- increasing attention to human flourishing, addressing the needs of all those involved, not just the powerful

- reflecting on the effects of the research on themselves and considering whether technical, practical, and emancipatory outcomes of their work are desirable and feasible

- recognizing other types of knowledge and knowledge outcomes (e.g., emotional and artistic) as well as propositional and practical knowledge

- reconceptualizing their notions of worthwhile research

- recognizing other potential consequences of their research (e.g., community ties and critical awareness) as well as practical achievements and academic knowledge

The new action research uses new kinds of data and data analysis, inquiry skills, and types of knowledge. A change would be required similar to some researchers' earlier move from quantitative to qualitative data. If the new action research is to be accepted, the IS academic community would need to acknowledge its current bias toward wordbased, propositional knowledge and recognize the other types as being of equal value to (or greater value than) propositional knowledge.

The new action research is based on a different worldview, based on action and participation. A paradigm change would be required, similar to some IS researchers' earlier move from positivism to interpretivism. The belief that research into human experience should be carried out by those doing the experiencing implies that everyone is capable of being a researcher; research is not an exclusive preserve of academics. IS researchers would have to ask whether they are willing to let go and share their position as researchers. 
Finally, a turn to action would imply more than the use of new types of data and a new worldview. It would raise fundamental questions about the role of IS researchers, why we do research, and for whose benefit.

IS researchers currently choose from a range of strategies and paradigms. The new action research widens the range. It is unlikely that everyone will choose to adopt it, but those that do will be able to explore its relevance to IS research and the appropriateness of the five quality issues discussed here. It may be difficult for it to gain respectability, just as current IS action research is not seen by everyone as acceptable research. IS researchers will need to consider whether their own career objectives are attainable if they choose to do new action research. However, this paper has discussed how IS action research could be enriched by taking the turn to action.

\section{REFERENCES}

Adam, A., Howcroft, D., Richardson, H., and Robinson, B. (Eds.). (Re-)Defining Critical Research in Information Systems: Workshop Proceedings, University of Salford, Salford, UK, July 9-10, 2001.

Avison, D. "The 'Discipline' of Information Systems: Teaching, Research and Practice," in J. Mingers and F. A. Stowell (Eds.), Information Systems: An Emerging Discipline?, London: McGraw-Hill, 1997, pp. 113-135.

Avison, D., Baskerville, R., and Myers, M. “Controlling Action Research Projects," Information Technology and People (14:1), 2001, pp. 28-45.

Baskerville, R. "Investigating Information Systems with Action Research," Communications of the Association for Information Systems (2:19), 1999.

Baskerville, R., and Stage, J. "Controlling Prototype Development through Risk Analysis," MIS Quarterly (20:4), 1996, pp. 481-502.

Baskerville, R. L., and Wood-Harper, A. T. "A Critical Perspective on Action Research as a Method for Information Systems Research," Journal of Information Technology (11), 1996, pp. 235-246.

Baskerville, R., and Wood-Harper, A. T. "Diversity in Information Systems Action Research Methods," European Journal of Information Systems (7), 1998, pp. 90-107.

Bjerknes, G., Ehn, P., and Kyng, M. Computers and Democracy, Aldershot, UK: Avebury, 1987.

Bradbury, H., and Reason, P. "Conclusion: Broadening the Bandwidth of Validity: Issues and Choice-Points for Improving the Quality of Action Research," in P. Reason and H. Bradbury (Eds.), Handbook of Action Research: Participatory Inquiry and Practice, London: Sage Publications, 2001, pp. 447-455.

Brechin, A. "Sharing," in P. Shakespeare, D. Atkinson, and S. French (Eds.), Reflecting on Research Practice: Issues in Health and Social Welfare, Buckingham, UK: Open University Press, 1993, pp. 70-82.

Carr, W., and Kemmis, S. Becoming Critical: Education, Knowledge and Action Research, London: Falmer, 1986.

Checkland, P. Systems Thinking, Systems Practice, Chichester: Wiley, 1981.

Checkland, P., and Holwell, S. Information, Systems, and Information Systems: Making Sense ofthe Field, Chichester. Wiley, 1998.

Checkland, P. B., and Jenkins, G. M. "Learning by Doing: Systems Education at Lancaster University," Journal of Systems Engineering (4:1), 1974, pp. 40-51.

Checkland, P., and Scholes, J. Soft Systems Methodology in Action, Chichester: Wiley, 1990. 
Fals-Borda, O. "Participatory (Action) Research in Social Theory: Origins and Challenges," in P. Reason and H. Bradbury (Eds.), Handbook of Action Research: Participatory Inquiry and Practice, London: Sage Publications, 2001, pp. 27-27.

Findlay, A. "An Information System for Northton Borough Council Structures Department," Unpublished B.Sc. Individual Project Report, School of Computing and Maths, University of Teesside (Pseudonym used), 1998.

Heron, J. Co-operative Inquiry: Research into the Human Condition, London: Sage Publications, 1996.

Heron, J., and Reason, P. "The Practice of Co-operative Inquiry: Research 'with' Rather than 'on' People," in P. Reason and H. Bradbury (Eds.), Handbook of Action Research: Participatory Inquiry and Practice, London: Sage Publications, 2001, pp. 179-188.

Holyoak, K. J., and Thagard, P. Mental Leaps: Analogy in Creative Thought, Cambridge, MA; MIT Press, 1996.

Howard, R. "UTOPIA: Where Workers Craft New Technology," Technology Review (14:1), 1985, pp. 43-49

Howcroft, D., and Wilson, M. "Paradoxes of Participatory Practices: The Janus Role of the Systems Developer," Information and Organization (13:1), 2003, pp. 1-24.

Kemmis, S. "Exploring the Relevance of Critical Theory for Action Research: Emancipatory Action Research in the Footsteps of Juergen Habermas," in P. Reason and H. Bradbury (Eds.), Handbook of Action Research: Participatory Inquiry and Practice, London: Sage Publications, 2001, pp. 91-102.

Kock, N. F. "Myths in Organizational Action Research: Reflections on s Study of ComputerSupported Process Redesign Groups," Organizations and Society (4:9), 1997, pp. 65-91.

Kock, N. F., McQueen, R. J., and Scott, J. L. "Can Action Research Be Made More Rigorous in a Positivist Sense? The Contribution of an Iterative Approach," Journal of Systems and Information Technology (1:1), 1997, pp. 1-24.

Lau, F. "A Review on the Use of Action Research in Information Systems Studies," in A. Lee, J. Liebenau, and J. I. DeGross (Eds.), Information Systems and Qualitative Research, London: Chapman \& Hall, 1997, pp. 31-68.

Lewis, H. M. "Participatory Research and Education for Social Change: Highlander Research and Education Centre," in P. Reason and H. Bradbury (Eds.), Handbook ofAction Research: Participatory Inquiry and Practice, London: Sage Publications, 2001, pp. 356-362.

Lincoln, Y. S. "From the Discourse of 'the Other' to the Other Discourse: Stakeholder-Based Models of Evaluation and the Human Side of Social Welfare," Scandinavian Journal of Social Welfare (7:2), 1998, pp. 114-117.

Lincoln, Y. S., and Denzin, N. K. "The Fifth Moment," in N. K. Denzin and Y. S. Lincoln (Eds.), Handbook of Qualitative Research, Thousand Oaks, CA: Sage Publications, 1994, pp. $575-586$.

Lyons, P. "Internet Retailing Opportunities for Northern DIY,” Unpublished B.Sc. Individual Project Report, School of Computing and Maths, University ofTeesside (Pseudonym used), 1998.

Marshall, J., and McLean, A. "Reflection in Action: Exploring Organizational Culture," in P. Reason (Ed.), Human Inquiry in Action: Developments in New Paradigm Research, London: Sage Publications, 1988, pp. 199-220.

Mathiassen, L. "Reflective Systems Development," Scandinavian Journal of Information Systems (10:1\&2), 1998, pp. 67-118.

Mingers, J. "The Paucity of Multimethod Research: A Review of the Information Systems Literature," Information Systems Journal (13:3), 2003, pp. 233-249.

Morgan, G. Images of Organization, Beverly Hills, CA: Sage Publications, 1986.

Morgan, G. Imaginization: The Art of Creative Management, Newbury Park, CA: Sage Publications, 1993. 
Mumford, E. “Advice for an Action Researcher," Information Technology and People (14:1), 2001, pp. 12-27.

Mumford, E. Designing Human Systems, Manchester, UK: Manchester Business School, 1983.

Mumford, E. "Job Satisfaction: A Method of Analysis," in K. Legge and E. Mumford (Eds.), Designing Organizations for Satisfaction and Efficiency, Teakfield, UK: Gower Press, 1978, pp. 18-35.

Oates, B. J. "Co-operative Inquiry: Reflections on Practice," Electronic Journal of Business Research Methods (1:1), 2002, pp. 33-42 (available online at http://www.ejbrm.com).

Oates, B. J. Metaphors for Organizations During Information Systems Development, Unpublished Ph.D. Thesis, University of Teesside, Middlesbrough, UK, 2000.

Oates, B. J. "Participation in Information Systems Research," in A. T. Wood-Harper, N. Jayaratna, and J. R. G. Wood (Eds.), Methodologies for Developing and Managing Emerging Technology Based Systems, London: Springer Verlag, 1999, pp. 269-279.

Orlikowski, W. J., and Baroudi, J. J. "Studying Information Technology in Organizations: Research Approaches and Assumptions," Information Systems Research (2:1), 1991, pp. 1-28.

Rapoport, A. "Three Dilemmas of Action Research," Human Relations (23:6), 1970, pp. 499513.

Reason, P. (Ed.). Human Inquiry in Action: Developments in New Paradigm Research, London: Sage Publications, 1988.

Reason, P. "Human Inquiry as Discipline and Practice," in P. Reason (Ed.), Participation in Human Inquiry, London: Sage Publications, 1994a, pp. 40-56.

Reason, P. (Ed.). Participation in Human Inquiry. Sage, London, 1994b.

Reason, P. "Three Approaches to Participative Inquiry," in N. K. Denzin and Y. S. Lincoln (Eds.), Handbook of Qualitative Research, Thousand Oaks, CA: Sage Publications, 1994c, pp. 342-339.

Reason, P., and Bradbury, H. (Eds.). Handbook of Action Research: Participatory Inquiry and Practice, London: Sage Publications, 2001a.

Reason, P., and Bradbury, H. "Introduction: Inquiry and Participation in Search of a World Worthy of Human Aspiration," in P. Reason and H. Bradbury (Eds.), Handbook of Action Research: Participatory Inquiry and Practice, London: Sage Publications, 2001b, pp. 114.

Reason, P., and Heron, J. “A Layperson's Guide to Co-operative Inquiry," Centre for Action Research in Professional Practice, School of Management, University of Bath, 1999.

Reason, P., and Rowan, J. (Eds.). Human Inquiry: A Sourcebook ofNew Paradigm Research, Chichester: Wiley, 1981.

Schön, D. A. The Reflective Practitioner: How Professionals Think in Action, New York: Basic Books, 1983.

Thomas, M. An Information System for a Diabetics Unit, “Unpublished B.Sc. Individual Project Report, School of Computing and Maths, University of Teesside, 1998.

Torbert, W. R. The Power of Balance: Transforming Self, Society, and Scientific Inquiry, Newbury Park, CA: Sage Publications, 1991.

Traylen, H. "Co-operative Inquiry with Health Visitors," in P. Reason (Ed.), Participation in Human Inquiry, London: Sage Publications, 1994, pp. 59-81.

Treleaven, L. "Making a Space: A Collaborative Inquiry with Women as StaffDevelopment," in P. Reason (Ed.), Participation in Human Enquiry, London: Sage Publications, 1994, pp. 138-162.

Treleaven, L. "The Turn to Action and the Linguistic Turn: Towards an Integrated Methodology," in P. Reason and H. Bradbury (Eds.), Handbook of Action Research: Participatory Inquiry and Practice, London: Sage Publications, 2001, pp. 260-272.

Vidgen, R. "Constructing a Web Information System Development Methodology," Information Systems Journal (12), 2002, pp. 247-261. 
Walsham, G. "The Emergence of Interpretivism in IS Research," Information Systems Research (6:4), 1995, pp. 376-394.

Waring, T. "Gender Reflexivity: A Missing Element from Action Research in Information Systems," Electronic Journal of Business Research Methods (1:1), November 2002, pp. 5058 (available online at http://www.ejbrm.com).

Waring, T. S. The Systems Analyst and Emancipatory Practice: An Exploratory Study in Three NHS Hospitals, Unpublished Ph.D. Thesis, University of Northumbria, Newcastle, 2000.

Webb, G. "Becoming Critical of Action Research for Development," in O. Zuber-Skerritt (Ed.), New Directions in Action Research, London: Falmer Press, 1996, pp. 137-161.

Wood-Harper, A. T. "Research Methods in Information Systems: Using Action Research," in E. Mumford, R. Hirschheim, G. Fitzgerald and A. T. Wood-Harper (Eds.), Research Methods in Information Systems, Amsterdam: Elsevier Science Publishers, 1985, pp. 169191.

\section{ABOUT THE AUTHOR}

Briony J. Oates is a senior lecturer in Information Systems in the School of Computing at the University of Teesside, Middlesbrough, UK. She holds a BA (Hons) in German language and literature (1978, Newcastle), an M.Sc. in information technology (1988, Teesside), and a Ph.D. in information systems (2000, Teesside), and has worked as both an academic and a practitioner. Her Ph..D thesis examined the role of organizational metaphors as cognitive structuring devices during information systems development. Her current research interests include the social and organizational aspects of information systems development, development methods for Web-based systems, and e-government. She is also currently preparing a book on research methods, Researching Information Systems and Computing, which Sage plans to publish in 2005. Briony can be reached by e-mail at B.J.Oates@tees.ac.uk. 